\title{
Determining indicator toxaphene congeners in soil using comprehensive two-dimensional gas chromatography-tandem mass spectrometry
}

\author{
Shuai Zhu ${ }^{\mathrm{a}, \mathrm{b}}$, Lirong Gao ${ }^{\mathrm{a}, *}$, Minghui Zheng ${ }^{\mathrm{a}}$, Huimin Liu ${ }^{\mathrm{b}}$, Bing Zhang ${ }^{\mathrm{a}}$, \\ Lidan Liu $^{\mathrm{a}}$, Yiwen Wang ${ }^{\mathrm{a}}$ \\ a State Key Laboratory of Environmental Chemistry and Ecotoxicology, Research Center for Eco-Environmental Sciences, Chinese Academy of Sciences, \\ Beijing 100085, China \\ ${ }^{\mathrm{b}}$ Agricultural University of Hebei, Baoding 071000, China
}

\section{A R T I C L E I N F O}

\section{Article history:}

Received 9 June 2013

Received in revised form

18 September 2013

Accepted 22 September 2013

Available online 12 October 2013

\section{Keywords:}

Comprehensive two-dimensional gas

chromatography

Tandem mass spectrometry

Indicator toxaphene congeners

Soil

GC $\times$ GC

\begin{abstract}
A B S T R A C T
Toxaphene, which is a broad spectrum chlorinated pesticide, is a complex mixture of several hundred congeners, mainly polychlorinated bornanes. Quantifying toxaphene in environmental samples is difficult because of its complexity, and because each congener has a different response factor. Toxaphene chromatograms acquired using one-dimensional gas chromatography (1DGC) show that this technique cannot be used to separate all of the toxaphene congeners. We developed and validated a sensitive and quantitative method for determining three indicator toxaphene congeners in soil using an isotope dilution/comprehensive two-dimensional gas chromatography-tandem mass spectrometry (GC $\times$ GCMS). The samples were extracted using accelerated solvent extraction, and then the extracts were purified using silica gel columns. ${ }^{13} \mathrm{C}_{10}$-labeled Parlar 26 and 50 were used as internal standards and ${ }^{13} \mathrm{C}_{10}$-labeled Parlar 62 was used as an injection standard. The sample extraction and purification treatments and the GC $\times$ GC-MS parameters were optimized. Subsequently the samples were determined by GC $\times$ GC-MS. The limits of detection for Parlar 26,50 , and 62 were $0.6 \mathrm{pg} / \mathrm{g}, 0.4 \mathrm{pg} / \mathrm{g}$, and $1.0 \mathrm{pg} / \mathrm{g}(S / N=3)$, respectively, and the calibration curves had good linear correlations between 50 and $1000 \mu \mathrm{g} / \mathrm{L}\left(r^{2}>0.99\right)$. Comprehensive two-dimensional GC gave substantial improvements over onedimensional GC in the toxaphene analysis. We analyzed soil samples containing trace quantities of toxaphene to demonstrate that the developed method could be used to analyze toxaphene in environmental samples.
\end{abstract}

(c) 2013 Elsevier B.V. All rights reserved.

\section{Introduction}

Toxaphene is a complex mixture that primarily consists of chlorinated bornanes, with some chlorinated camphenes, dihydrocamphenes, bornenes, and bornadienes [1]. The number of theoretically possible polychlorinated bornane congeners is 32,768 , most of which are chiral [2]. Toxaphene was first produced in the United States by the Hercules Powder Company in the mid1940s, and was widely used as an insecticide on cotton, soybean, and corn crops [3]. Toxaphene was the most applied pesticide in the USA and other countries in the mid-1970s. The total global production has been estimated to be $0.45-1.33 \times 10^{6} \mathrm{t}[1]$, of which $2.0 \times 10^{4} \mathrm{t}$ were produced in China. Toxaphene congeners are ubiquitous in the environment [4] because of their widespread

\footnotetext{
*Corresponding author. Tel.: +86 10 62849356; fax: +86 1062849172 .

E-mail address: gaolr@rcees.ac.cn (L. Gao).
}

use and environmental stability, and they have been found worldwide in air, soil, and biota (including aquatic organisms, particularly marine mammals, such as beluga whales) [5-11]. The use of toxaphene was restricted in the 1980s because of its toxicity, and persistence, and because of its potential to bioaccumulation and undergo long-range transport $[8,12]$; and it is classed as a persistent organic pollutant (POPs) under the Stockholm Convention [13].

The analysis of toxaphene is a difficult task because of the complexity of the commercial mixtures and the lack of quantification standards. Up to now, a number of types of instrumentation and analytical methods have been used to quantify toxaphene in environmental samples. Toxaphene can be analyzed using gas chromatography (GC) with an electron capture detector (ECD), but the preferred detector is currently a mass spectrometer (MS) because of the selectivity and sensitivity that can be achieved $[3,14]$. Each of these detectors has both advantages and inherent problems. GC-ECD offers high sensitivity and low costs, but it is 
equally selective for toxaphene compounds and other organochlorine compounds, leading to the possibility of concentrations being overestimated because of interferences. Another drawback is that GC-ECD analysis cannot give information on the toxaphene congener composition in a sample. In contrast, the MS detection is based on the mass-to-charge ratios of the ionized compounds, but in this case, the fragmentation of the molecular ion provided the main differences of the response factor of the target ion [8]. High resolution GC has been used to study the composition of technical toxaphene, but it is not possible to satisfactorily separate the toxaphene congeners even with the separation performance that can be achieved using this technique. To overcome these problems, tandem MS $[8,15,16]$ and high resolution MS $[17,18]$ have been used to determine toxaphene separated using GC, but these techniques still cannot provide accurate quantification or effective separation of the complicated toxaphene mixtures.

In the analysis of trace pollutants in environmental samples, it is a challenge to extract target analytes that are present at very low concentrations and separate them from complex matrices. It is, therefore, very difficult to quantify toxaphene residues in environmental matrices accurately using common methods. Most of the problems in this analysis are caused by the complexity of the original toxaphene mixture, interference by other organohalogen compounds and/or matrix constituents, and the very different concentrations of compounds that co-elute in the clean-up procedures. Comprehensive two-dimensional GC $(\mathrm{GC} \times \mathrm{GC})$ can be used to solve these problems because it is an extremely powerful separation technique in which two GC columns, with different separation mechanisms, are connected using an interface called a modulator [13,19]. GC $\times$ GC has a higher analyte capacity and potential resolving power than conventional one-dimensional (1D) GC [20]. GC $\times$ GC has been successfully used to analyze POPs in complex samples [13,21-25].

Although there are a large number of toxaphene congeners, it has been shown that the congeners Parlar 26, Parlar 50, and Parlar 62 (Fig. 1) are predominate congeners. The sum of the concentration of these three compounds normally being approximately 8$50 \%$ of the total toxaphene concentration, and these are called indicator toxaphene congeners [17]. In the document "Guidance on the Global Monitoring Plan for Persistent Organic Pollutants" published in 2007 [26], it was suggested that the toxaphene congeners Parlar 26, 50, and 62 should be analyzed in environmental media. However, to the best of our knowledge, "total" toxaphene, using a technical toxaphene standard as a reference, has been measured and reported in most studies [11], most of which have been focused on aquatic organisms. Few reports of concentrations of the toxaphene indicator congeners in soil samples are available in the open literature. Moreover, the methods used in most of the studies that have been published have not involved using isotope-labeled internal standards that was to avoid matrix effects when analyzing real environmental sample extracts. Because of the problems outlined above, it is critical that a robust, sensitive analytical method for determining the toxaphene indicator congeners at trace concentrations in soil samples is developed.

The objective of the research described here was to assess the feasibility of using GC $\times$ GC-MS to accurately determine the toxaphene indicator congeners Parlar 26, 50, and 62 in typical soil samples. Different initial temperatures, injection modes, gas flow rates, and other instrumental parameters were evaluated and the optimum combination of parameters was selected. The sample preparation (i.e., extraction and cleanup) techniques were also evaluated and optimized. Soil samples were then analyzed for the indicator toxaphene congeners using the optimized method, and the results were compared with the results of analyzing the same extracts using other methods.

\section{Materials and methods}

\subsection{Chemicals and reagents}

Pesticide analysis grade acetone, n-hexane, methanol, and dichloromethane (DCM) were purchased from J. T. Baker (Phillipsburg, NJ, USA) and nonane was purchased from Sigma (St. Louis, MO, USA). Silica gel $(100-200 \mu \mathrm{m})$, concentrated $\mathrm{H}_{2} \mathrm{SO}_{4}$, and anhydrous $\mathrm{Na}_{2} \mathrm{SO}_{4}$ were "guaranteed reagents" (minimum 99.8\% pure), purchased from local manufacturers. Anhydrous $\mathrm{Na}_{2} \mathrm{SO}_{4}$ was dried at $660{ }^{\circ} \mathrm{C}$ for $7 \mathrm{~h}$ before use, and the silica gel was cleaned with dichloromethane and methanol, dried at $35^{\circ} \mathrm{C}$ for $12 \mathrm{~h}$, then activated at $550{ }^{\circ} \mathrm{C}$ for $7 \mathrm{~h}$. Acidified silica gel was prepared by adding $44 \mathrm{~g} \mathrm{H}_{2} \mathrm{SO}_{4}$ to $56 \mathrm{~g}$ activated silica gel (44\% w/w) or $22 \mathrm{~g} \mathrm{H}_{2} \mathrm{SO}_{4}$ to $78 \mathrm{~g}$ activated silica gel $(22 \% \mathrm{w} / \mathrm{w})$. Standard solutions of Parlar 26 (ULM-7828), Parlar 50 (ULM-7829), Parlar 62 (ULM-7830), ${ }^{13} \mathrm{C}_{10}$-Parlar 26 (CLM-7930), ${ }^{13} \mathrm{C}_{10^{-}}$ Parlar 50 (CLM-7931), and ${ }^{13} \mathrm{C}_{10}$-Parlar 62 (CLM-7932) were obtained from Cambridge Isotope Laboratories (Andover, MA, USA). Technical toxaphene was purchased from Dr. Ehrenstorfer (Augsburg, Germany).

\subsection{Sample extraction}

Soil sample was collected from an area in China that was not polluted with toxaphene, and the toxaphene congener concentrations in the soil were found to be below the detection limits. The sample was freeze-dried and homogenized by passing it through a stainless steel 80 -mesh sieve. The analysis procedure involved extracting the toxaphene congeners from the sample, then purifying and concentrating the extract before instrumental analysis.
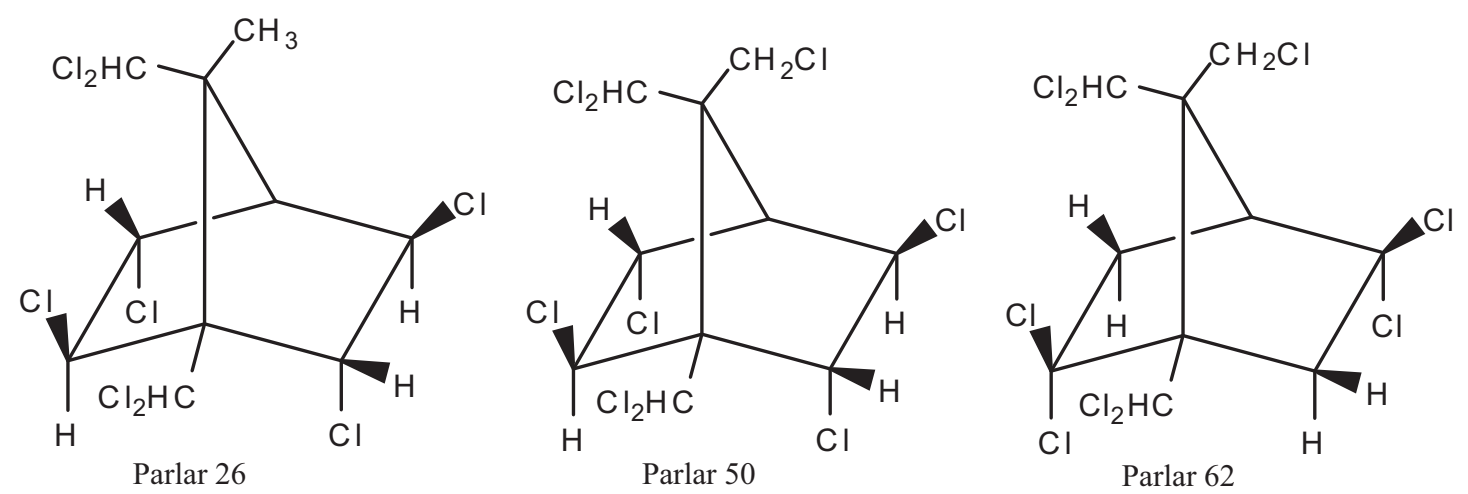

Fig. 1. Chemical structures of the indicator toxaphene congeners. 
Accelerated solvent extraction (ASE) was carried out on a Dionex ASE350 instrument (Dionex, Sunnyvale, CA, USA). The stainless steel extraction vessels were cleaned using DCM, then a piece of cellulose filter paper was placed at the bottom of each vessel. $5 \mathrm{~g}$ soil samples were accurately weighed and spiked with technical toxaphene, and then each sample was mixed with $3 \mathrm{~g}$ of diatomaceous earth and transferred to a stainless steel vessel. The empty volume remaining in each vessel was filled with diatomaceous earth and the cell was left at room temperature for $24 \mathrm{~h}$ to allow the toxaphene to interact with the soil. The samples were extracted with n-hexane/acetone (1/ $1 \mathrm{v} / \mathrm{v}$ ) at $100{ }^{\circ} \mathrm{C}$ and $10.3 \mathrm{MPa}$, with $7 \mathrm{~min}$ of heating, $8 \mathrm{~min}$ at a stable temperature, and three extraction cycles.

\subsection{Extract clean-up}

Two chromatography columns multilayer acidic silica gel column and activated silica gel column were studied to develop an efficient cleanup procedure for the toxaphene analysis in the soil samples. Multilayer acidic silica gel columns were packed with, from bottom to top, $12.5 \mathrm{~g}$ of $44 \%$ acidified silica gel, $10 \mathrm{~g}$ of $22 \%$ acidified silica gel, $2.5 \mathrm{~g}$ of activated silica gel, and $5 \mathrm{~g}$ of anhydrous $\mathrm{Na}_{2} \mathrm{SO}_{4}$ powder. Activated silica gel columns were packed with $8 \mathrm{~g}$ of activated silica gel and topped with $5 \mathrm{~g}$ of anhydrous $\mathrm{Na}_{2} \mathrm{SO}_{4}$ powder. Each multilayer column was rinsed with $50 \mathrm{~mL}$ of $\mathrm{n}$-hexane before use, then a sample was added and eluted with $100 \mathrm{~mL}$ of n-hexane, the eluate then being concentrated to about $2 \mathrm{~mL}$ in a rotary evaporator. Each activated silica gel column was washed with $50 \mathrm{~mL}$ of hexane before use, then a sample was applied and eluted with $45 \mathrm{~mL}$ of hexane, which was discarded, then with $50 \mathrm{~mL}$ toluene/n-hexane (35/65 v/v), which was collected for toxaphene analysis.

\subsection{Instrumental analysis}

The target analytes were determined using comprehensive GC $\times$ GC-MS. The GC $\times$ GC separation was performed using an Agilent 7890 GC (Agilent Technologies, Santa Clara, CA, USA) equipped with a dual-jet two-stage loop and a ZX2 thermal modulator (Zoex Corporation, Houston, TX, USA), and the detector was an Agilent 5975C MS detector. The loop modulator principles have been described by Korytár et al. [22] and Omar et al. [27]. The ZX2 thermal modulator was fitted with a deactivated fused silica column (1.0 m long, $0.10 \mathrm{~mm}$ id, $0.10 \mu \mathrm{m}$ film thickness) and had a pulse duration of $300 \mathrm{~ms}$, a hot jet temperature of $320^{\circ} \mathrm{C}$, and a $6 \mathrm{~s}$ modulation period. Liquid nitrogen was used to cool the nitrogen gas for the cold pulses, to keep the cold-jet temperature at $0-10{ }^{\circ} \mathrm{C}$. The carrier gas was helium (99.999\% pure), which was used at a constant flow rate $(1.0 \mathrm{~mL} / \mathrm{min})$. Injections $(1 \mu \mathrm{L})$ were performed in pulse splitless mode, with the injector at $280^{\circ} \mathrm{C}$. The GC columns used were a DB-XLB (30 m long, $0.25 \mathrm{~mm}$ id, $0.25 \mu \mathrm{m}$ film thickness, J\&W, Agilent Technologies); and a BPX50 (2 m long, $0.10 \mathrm{~mm}$ id, $0.1 \mu \mathrm{m}$ film thickness, SGE, Analytical Science, Victoria, Australia). The GC oven was initially held at $80^{\circ} \mathrm{C}$ for $2 \mathrm{~min}$, and increased at $2{ }^{\circ} \mathrm{C} / \mathrm{min}$ to $290{ }^{\circ} \mathrm{C}$, which was held for $2 \mathrm{~min}$, then increased at $5{ }^{\circ} \mathrm{C} / \mathrm{min}$ to $300{ }^{\circ} \mathrm{C}$, which was held for $10 \mathrm{~min}$. The mass spectrometer was used in negative chemical ionization mode and tuned and calibrated using organohalogen compounds, using an ionization energy of $235.0 \mathrm{eV}$, and an ion source temperature of $150{ }^{\circ} \mathrm{C}$.

\section{Results and discussion}

\subsection{Sample extraction}

As already mentioned, it is a challenge to analyze very low concentrations of pollutants in complex environmental matrices. ASE is a relatively new extraction technique that offers faster sample processing than traditional solvent extraction methods and the potential for the automated, unattended extraction of multiple solid samples $[28,29]$. ASE is now frequently used for a variety of environmental analyses [30].

One way of achieving improved analyte extractabilities from soil samples is to use ASE under optimized conditions. We evaluated the effectiveness of using n-hexane/DCM, n-hexane/acetone and acetone to extract toxaphene from soil using ASE (Fig. 2(a)), and the highest recoveries were obtained using n-hexane/acetone. This was expected because toxaphene and n-hexane both have low polarities, and toxaphene is more soluble in n-hexane than the other solvents tested. Besides, the strong ability to dissolve of acetone contributes to the dissolution of toxaphene.

Different extraction temperatures $\left(80,100,120\right.$, and $\left.150{ }^{\circ} \mathrm{C}\right)$ were tested, to evaluate the influence of the extraction temperature on the recoveries of toxaphene congeners. The extraction temperature had a strong effect on the recoveries, as is shown in Fig. 2(b). Increasing the extraction temperature from 80 to $100{ }^{\circ} \mathrm{C}$ improved the recovery of all of the toxaphene congeners, possibly because increasing the extraction temperature led to the increased diffusion and dissolution of toxaphene, accelerating its transfer from the soil particle surfaces into the extraction solvent. But when the temperature rose from 100 to $150{ }^{\circ} \mathrm{C}$ more interference
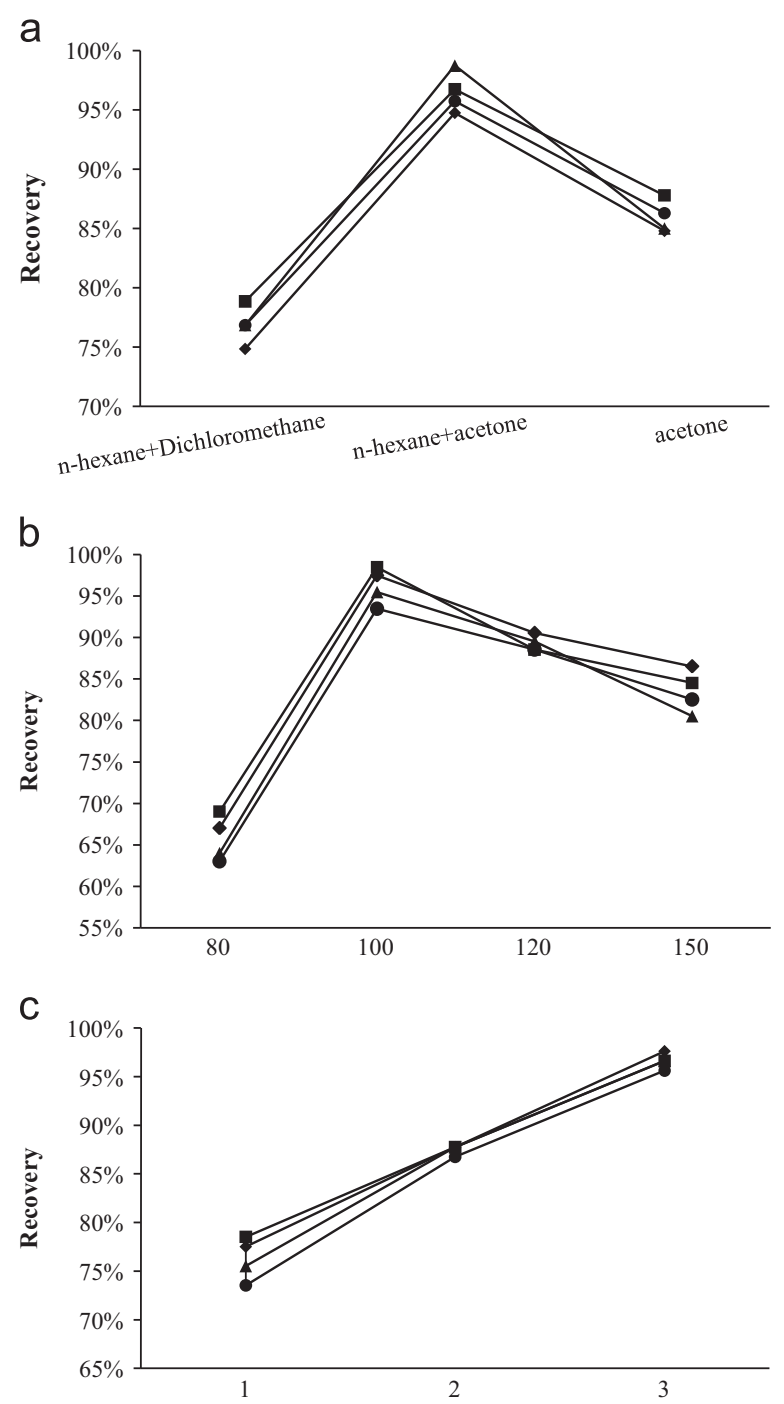

Fig. 2. Effects on the toxaphene recovery of (a) the accelerated solvent extraction solvent, (b) the accelerated solvent extraction temperature, and (c) the number of accelerated solvent extraction cycles. 
peak appeared in the GC chromatograms and the background noise also increased. This indicates that the use of high extraction temperatures had resulted in the co-extraction of other organic substances from soil. And the extraction efficiency was more than $90 \%$ when the temperature was set as $100{ }^{\circ} \mathrm{C}$. So a temperature of $100{ }^{\circ} \mathrm{C}$ was applied for analysis of toxaphene in this study.

Tests were performed using one, two, and three extraction cycles, and the best recoveries were found using three extraction cycles (Fig. 2(c)). Two extraction cycles gave quite high recoveries (86\%), but three extraction cycles gave satisfactory recoveries of the toxaphene congeners, at $92.6-97.7 \%$, so this was used in the optimized method.

\subsection{Sample purification}

We attempted to find the optimal purification step to separate the analytes from interfering substances. This is a very important part of the analysis because the detection limit is closely related to the effectiveness of the clean-up. Environmental samples have complicated matrices, and low concentrations of toxaphene and high concentrations of co-extracted compounds are found in extracts. We used two silica gel columns to purify the soil sample extracts, and

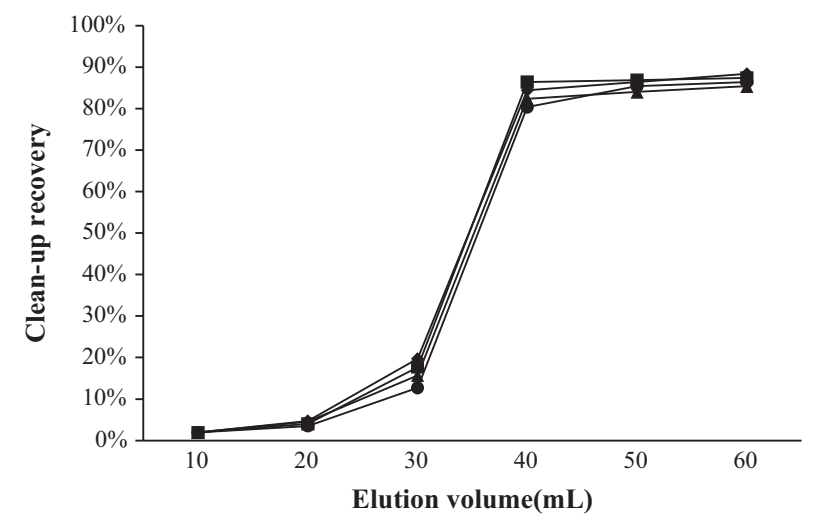

Fig. 3. Effect of different silica gel chromatography elution volumes on the toxaphene recovery. compared the toxaphene recoveries using different elution volumes. The recoveries hardly increased at elution volumes greater than $40 \mathrm{~mL}$ (Fig. 3). In order to completely elute the target compound, with no or little co-eluting interfering substance, the volume of the eluting solvent was set to $50 \mathrm{~mL}$.

\subsection{Instrumental analysis}

\subsubsection{Optimizing the GC oven temperature program}

Four GC oven temperature programs were tested, and are shown in Fig. 4(a). Program 1 was $80^{\circ} \mathrm{C}$ for $2 \mathrm{~min}$, increased at $1{ }^{\circ} \mathrm{C} / \mathrm{min}$ to $290^{\circ} \mathrm{C}$, then increased at $5^{\circ} \mathrm{C} / \mathrm{min}$ to $300{ }^{\circ} \mathrm{C}$. Program 2 was $80{ }^{\circ} \mathrm{C}$ for $2 \mathrm{~min}$, increased at $2{ }^{\circ} \mathrm{C} / \mathrm{min}$ to $290{ }^{\circ} \mathrm{C}$, then increased at $5{ }^{\circ} \mathrm{C} / \mathrm{min}$ to $300^{\circ} \mathrm{C}$. Program 3 was $80^{\circ} \mathrm{C}$ for $2 \mathrm{~min}$, increased at $5{ }^{\circ} \mathrm{C} / \mathrm{min}$ to $290^{\circ} \mathrm{C}$, then increased at $5{ }^{\circ} \mathrm{C} / \mathrm{min}$ to $300{ }^{\circ} \mathrm{C}$. Program 4 was $80^{\circ} \mathrm{C}$ for $2 \mathrm{~min}$, increased at $10^{\circ} \mathrm{C} / \mathrm{min}$ to $290{ }^{\circ} \mathrm{C}$, then increased at $5{ }^{\circ} \mathrm{C} / \mathrm{min}$ to $300{ }^{\circ} \mathrm{C}$. Changing the first rate of temperature increase from $1{ }^{\circ} \mathrm{C} / \mathrm{min}$ to $10^{\circ} \mathrm{C} / \mathrm{min}$ (programs 1-4) caused the responses of the three indicator toxaphene congeners to gradually decrease, but there was a little difference in the responses using programs 1 and 2 (first stage rates of $1{ }^{\circ} \mathrm{C} / \mathrm{min}$ and $2{ }^{\circ} \mathrm{C} / \mathrm{min}$, respectively). A first stage heating rate of $1{ }^{\circ} \mathrm{C} / \mathrm{min}$ in one-dimensional and two-dimensional GC also gave the best separation of toxaphene congeners, as can be seen in the industrial toxaphene chromatogram shown in Fig. 5, but this rate also, of course, gives the longest analysis time. A first stage heating rate of $2{ }^{\circ} \mathrm{C} /$ min (program 2) gave good chromatographic separation and a shorter analysis time. A first stage heating rate of $5{ }^{\circ} \mathrm{C} / \mathrm{min}$ (program 3) caused significantly poorer separation of the toxaphene congeners, and at $10{ }^{\circ} \mathrm{C} / \mathrm{min}$ (program 4) the ability of the GC to separate the toxaphene congeners had effectively been lost. Taking the toxaphene responses, the separation of the toxaphene congeners, and the analysis time into consideration, $2^{\circ} \mathrm{C} / \mathrm{min}$ was chosen as the optimum first GC oven temperature program rate.

\subsubsection{Optimizing the initial GC temperature}

Four initial GC oven temperatures, $60,80,100$, and $120^{\circ} \mathrm{C}$, were tested, to study the influence of the initial oven temperature on the indicator toxaphene congener responses, and the results are shown in Fig. 4(b). The initial GC oven temperature had a little

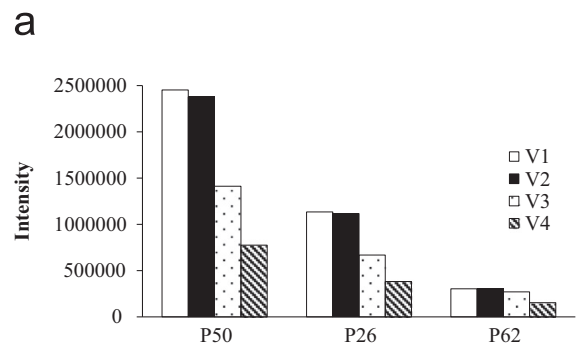

C

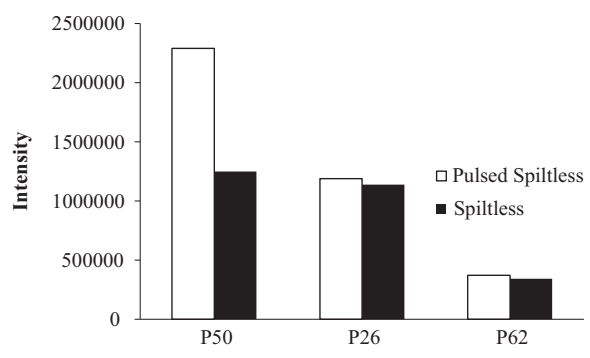

b

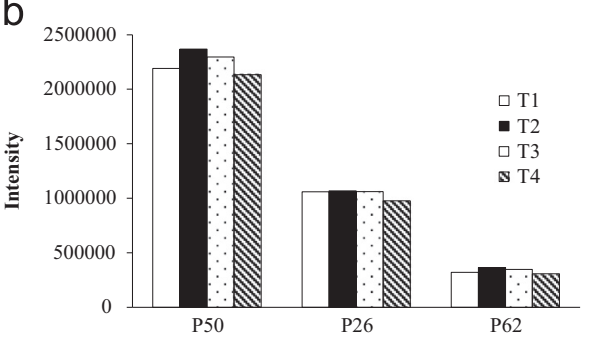

d

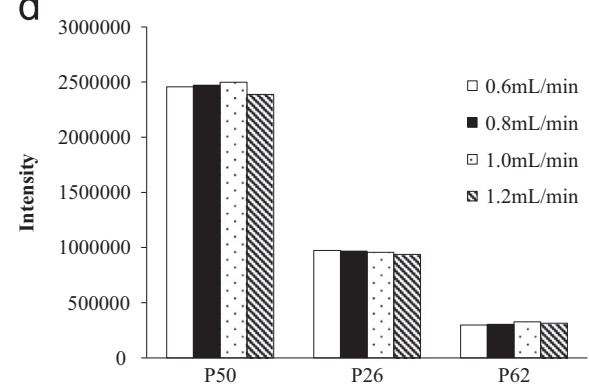

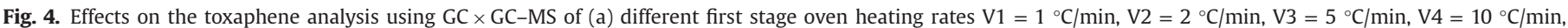
(b) different initial temperatures $\mathrm{T} 1=60{ }^{\circ} \mathrm{C}, \mathrm{T} 2=80^{\circ} \mathrm{C}, \mathrm{T} 3=100{ }^{\circ} \mathrm{C}, \mathrm{T} 4=120^{\circ} \mathrm{C}$, (c) different injection modes, and (d) different carrier gas flow rates ( $\mathrm{mL} / \mathrm{min}$ ). 

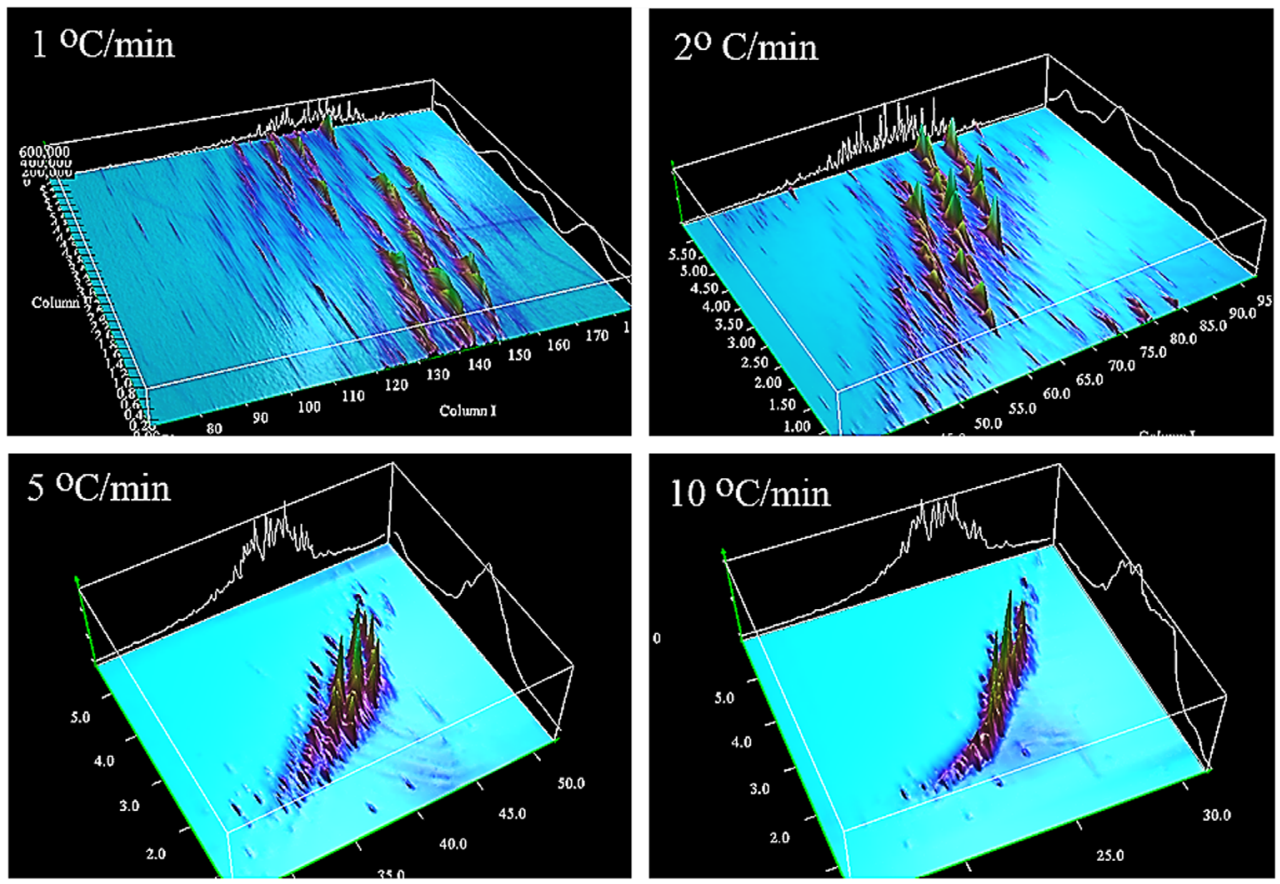

Fig. 5. GC $\times$ GC-MS chromatograms of technical toxaphene at different first stage oven heating rates.

Table 1

The linear regression equations for the toxaphene congener calibration curves, and the limits of detection and standard deviations achieved.

\begin{tabular}{llllr}
\hline Compound & Linear regression equation & $R^{2}$ & LOD $^{\mathrm{a}}(\mathrm{pg} / \mathrm{g})$ & LOQ $^{\mathrm{b}}(\mathrm{pg} / \mathrm{g})$ \\
\hline Parlar 26 & $y=1027.0 x+13,540$ & 0.992 & 0.6 & 1.9 \\
Parlar 50 & $y=2150.0 x-22,243$ & 0.993 & 0.4 & 1.2 \\
Parlar 62 & $y=305.9 x+2796$ & 0.990 & 1.0 & 2.9 \\
\hline
\end{tabular}

a Limit of detection.

${ }^{\mathrm{b}}$ Limits of quantitation.

${ }^{\mathrm{c}}$ Relative standard deviation.

Table 2

Results of the analysis of toxaphene indicator congeners in blank and spiked-matrix samples.

\begin{tabular}{|c|c|c|c|c|c|c|c|c|}
\hline \multirow[t]{2}{*}{ Compound } & \multicolumn{2}{|l|}{ Blank $^{\mathrm{a}}$} & \multicolumn{2}{|c|}{ Matrix spiked A } & \multicolumn{2}{|c|}{ Matrix spiked B } & \multicolumn{2}{|c|}{ Matrix spiked C } \\
\hline & $\begin{array}{l}\text { Concentration } \\
\text { (ng/g) }\end{array}$ & $\begin{array}{l}\text { Recovery } \\
(\%)\end{array}$ & $\begin{array}{l}\text { Concentration } \\
(\mathrm{ng} / \mathrm{g})\end{array}$ & $\begin{array}{l}\text { Recovery } \\
(\%)\end{array}$ & $\begin{array}{l}\text { Concentration } \\
(\mathrm{ng} / \mathrm{g})\end{array}$ & $\begin{array}{l}\text { Recovery } \\
(\%)\end{array}$ & $\begin{array}{l}\text { Concentration } \\
(\mathrm{ng} / \mathrm{g})\end{array}$ & $\begin{array}{l}\text { Recovery } \\
(\%)\end{array}$ \\
\hline Parlar 26 & $\mathrm{ND}^{\mathrm{b}}$ & 83 & 4.2 & 108 & 4.4 & 67 & 5.1 & 78 \\
\hline Parlar 50 & ND & 89 & 4.0 & 113 & 5.3 & 60 & 4.6 & 84 \\
\hline Parlar 62 & ND & 80 & 4.1 & 102 & 4.5 & 74 & 4.6 & 86 \\
\hline
\end{tabular}

${ }^{\text {a }}$ Recovery for blank sample was the recoveries of ${ }^{13} \mathrm{C}_{10}$ labeled Parlar 26, 50 and 62.

${ }^{\mathrm{b}} \mathrm{ND}=$ not detected.

effect on the toxaphene congener responses, so, taking the sample interferences into account, the initial oven temperature was set at $80^{\circ} \mathrm{C}$.

\subsubsection{Selecting the injection mode}

The injection mode is a key factor in sample analysis, and split, splitless, and pulsed splitless injection modes are commonly used for comprehensive two-dimensional GC. Because of the thermal instability of the toxaphene indictor congeners, we tested the splitless and pulsed splitless modes. As can be seen from Fig. 4(c), pulsed splitless mode gave a Parlar 50 response twice as high as that given by splitless injection, possibly because the pressure pulses cause the analyte to be moved onto the column at a faster rate, causing less decomposition in the injection port, and, at the same time, concentrating the analyte on the GC column. The pulsed splitless injection mode was, therefore, chosen for the optimized method.

\subsubsection{Optimizing the gas flow rate}

The efficiency of the GC separation of the toxaphene congeners at constant carrier gas flow rates of $0.6,0.8,1.0$, and $1.2 \mathrm{~mL} / \mathrm{min}$ were tested, and the results are shown in Fig. 4(d). It can be seen that the same two-dimensional GC separation efficiencies were achieved at each of the tested flow rates. However, higher 
line speeds require higher head pressures, especially at higher temperatures, and this had an adverse effect on the entire twodimensional GC system, so a flow rate of $1.0 \mathrm{~mL} / \mathrm{min}$ was chosen.

\subsection{Method validation}

\subsubsection{Calibration curves, linear ranges, and detection limits}

Matrix blank solutions containing the three toxaphene test congeners at concentrations of $50,100,200,500$, and $1000 \mu \mathrm{g} / \mathrm{L}$ were each analyzed seven times using the optimized instrumental conditions, and calibration curves were established on the five data points. The peak area for each substance had a good linear correlation with the concentration, with correlation coefficients $(r)$ all above 0.99. The limits of detection (LODs) were calculated as three times the signal-noise $(S / N)$ ratio from blank sample analyses. The limits of quantification (LOQs) for the indicator toxaphene congeners were defined as 10 times the signal-noise $(S / N)$ ratio for the blank samples. Detailed calibration data, LODs, and LOQs are given in Table 1. It can be seen that Parlar 62 had a very low response factor, limiting the sensitivity of the method for that compound. This is because Parlar 62 is relatively poor at receiving a negative charge compared to Parlar 26 and 50, as has been reported previously [14].

\subsubsection{Recoveries of the toxaphene congeners}

Spiked soil samples that did not "naturally" contain toxaphene were analyzed. The samples ( $20 \mathrm{~g})$ were spiked with $100 \mathrm{ng}$
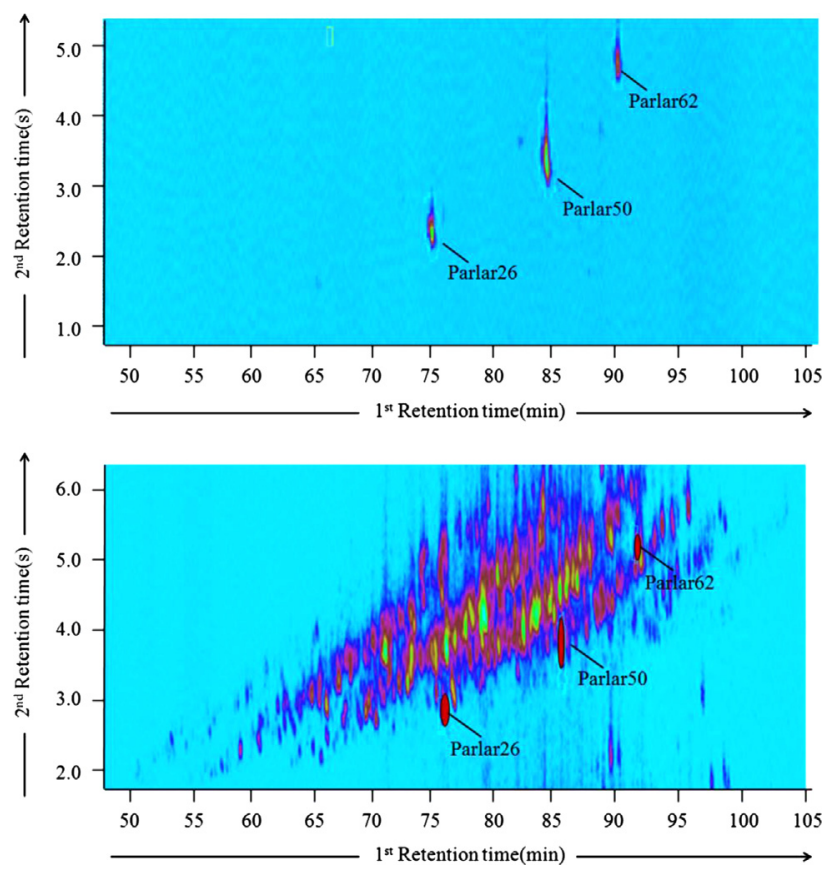

Fig. 6. GC $\times$ GC-MS chromatograms of Parlar 26, 50, and 62 in (A) the standard solution and (B) a soil sample. of unlabeled Parlar 26, 50, and 62 and $30 \mathrm{ng}$ of ${ }^{13} \mathrm{C}_{10}$-labeled Parlar 26 and 50 internal standards, then mixed with the amount of diatomaceous earth stated earlier. Blank samples were also analyzed, and these were $20 \mathrm{~g}$ of diatomaceous earth spiked with ${ }^{13} \mathrm{C}_{10}$-labeled Parlar 26 and 50 (30 ng).

As described above, after the samples had been cleaned-up they were spiked with $30 \mathrm{ng}$ of ${ }^{13} \mathrm{C}_{10}$-labeled Parlar 62, which was used as an injection standard (to calculate the recoveries of the internal standards). Each sample was analyzed five times. The average isotopically-labeled indicator toxaphene internal standard recoveries were $60-113 \%$. The individual results are shown in Table 2.

\subsection{Analyzing toxaphene congeners in soil samples}

Soil samples collected from a toxaphene production site were analyzed to verify that the method could be used to analyze real environmental samples. The samples were extracted and purified using the optimized method described above, concentrated to $40 \mu \mathrm{L}$ of nonane, then analyzed using the optimized instrumental conditions. The resulting chromatograms are shown in Fig. 6, and a large number of toxaphene congeners were detected. The concentrations of Parlar 26, 50, and 62 in the soil samples were listed in Table 4.

\subsection{Comparison of toxaphene determination using $1 D-G C$ and $G C \times G C$}

"Total" toxaphene has been reported in most publications in the last decade, but some individual toxaphene congeners have been produced and are now commercially available, enabling specific toxaphene components to be quantified. We compared the analytical methods that have been used for individual toxaphene congeners, and the results are summarized in Table 3. The methods that have been used previously have a number of shortcomings, including that they fail to separate all of the toxaphene congeners, and the chromatograms have a characteristic unresolved, broad profile, which clearly indicates the presence of a very large number of co-eluting and/or partly overlapping peaks. In contrast, the GC $\times$ GC-MS method we present here can be used to quantify a large number of compounds simultaneously, with acceptable LODs and good selectivity. GC $\times$ GC-MS is, therefore, a better choice than 1D-GC for studying toxaphene congeners in environmental samples, especially when the toxaphene concentrations are very low. 1D-GC is, however, the method of choice for analyzing technical toxaphene, even though it cannot satisfactorily separate the individual congeners.

Table 4

Concentrations of indicator toxaphene congeners in the samples (ng/g).

\begin{tabular}{llll}
\hline & Sample 1 & Sample 2 & Sample 3 \\
\hline Parlar 26 & 2.3 & 128 & 47 \\
Parlar 50 & 2.6 & 143 & 53 \\
Parlar 62 & 0.5 & 32 & 11 \\
\hline
\end{tabular}

Table 3

Analytical methods for determining toxaphene congeners.

\begin{tabular}{|c|c|c|c|c|}
\hline Instrument & Sample & Target & LODs & References \\
\hline GC-EI-HRMS & Fish & Parlar 26, Parlar 50, Parlar 62 & $0.04-0.30 \mathrm{ng} / \mathrm{g}$ & {$[30]$} \\
\hline GC-ECD & Marine mammals & Parlar 26, Parlar 50, Parlar 62 & $0.25-1 \mathrm{pg}$ & [9] \\
\hline GC-Ion trap MS/MS & Fish liver oil & Parlar 26, Parlar 32, Parlar 40, Parlar 44, Parlar 50, Parlar 62 & $2-49 \mathrm{pg} / \mu \mathrm{L}$ & [8] \\
\hline GC $\times$ GC-MS & Soil & Parlar 26, Parlar 50, Parlar 62 & $0.4-1.0 \mathrm{pg} / \mathrm{g}$ & This study \\
\hline
\end{tabular}




\section{Conclusions}

We developed an analytical procedure for toxaphene congeners that allows toxaphene indicator residues as low as $0.4 \mathrm{pg} / \mathrm{g}$ to be quantified in soil. The best resolution of the target analytes was obtained when a nonpolar chromatographic column was used first and a medium polarity chromatographic column was used second. Compared with traditional 1D-GC, GC $\times$ GC-MS is a powerful tool for determining toxaphene indicator congeners with high sensitivity and precision. Over 1000 congeners could be distinguished in technical toxaphene in a $2 \mathrm{~h}$ run. We verified that the method was suitable for the analysis of indicator toxaphene congeners in soil samples by analyzing real toxaphene-contaminated samples. This study shows that GC $\times$ GC has great potential for separating very complex mixtures of analytes, and the optimized method presented gives good detection limits, repeatable and accurate results, and a relatively simple sample pre-treatment process.

\section{Acknowledgments}

This research was supported by the Chinese Academy of Sciences (KZXZ-YW-JS406).

\section{References}

[1] W. Vetter, M. Oehme, Anthropogenic Compd. Part K 3 (2000) 237-287.

[2] W. Vetter, Chemosphere 26 (1993) 1079-1084.

[3] S.T. Glassmeyer, K.E. Shanks, R.A. Hites, Anal. Chem. 71 (1999) 1448-1453.

[4] D.C.G. Muir, J. de Boer, TrAC Trends Anal. Chem. 14 (1995) 56-66.

[5] L. Alder, H. Beck, S. Khandker, H. Karl, I. Lehmann, Chemosphere 34 (1997) $1389-1400$.

[6] L. Alder, B. Vieth, Fresenius J. Anal. Chem. 354 (1996) 81-92.
[7] D.A. Barbini, P. Stefanelli, S. Girolimetti, A. Di Muccio, R. Dommarco, Bull. Environ. Contam. Toxicol. 79 (2007) 226-230.

[8] F.J.G. Bernardo, M.A. Fernández, M.J. González, Chemosphere 61 (2005) 398-404.

[9] S. Føreid, T. Rundberget, T. Severinsen, Ø. Wiig, J. Utne Skaare, Chemosphere 41 (2000) 521-528.

[10] B. Fowler, Chemosphere 41 (2000) 487-492.

[11] B. Gouteux, D. Muir, S. Backus, E. Born, R. Dietz, T. Haug, T. Metcalfe, C. Metcalfe, N. Øien, Environ. Pollut. 153 (2008) 71-83.

[12] J.R. Kucklick, P.A. Helm, Anal. Bioanal. Chem. 386 (2006) 819-836.

[13] L.R. Bordajandi, L. Ramos, M.J. Gonzalez, J. Chromatogr. A 1125 (2006) 220-228.

[14] A.B. Fialkov, U. Steiner, L. Jones, A. Amirav, Int. J. Mass Spectrom. 251 (2006) $47-58$.

[15] D.C. MacEachen, N. Cocks, Chemosphere 49 (2002) 313-314.

[16] E. Pitarch, C. Medina, T. Portoles, F.J. Lopez, F. Hernandez, Anal. Chim. Acta 583 (2007) 246-258.

[17] B. Veyrand, A. Venisseau, P. Marchand, J.P. Antignac, B. Le Bizec, J. Chromatogr. B Anal. Technol. Biomed. Life Sci. 865 (2008) 121-126.

[18] M. Oehme, R. Baycan-Keller, Chemosphere 41 (2000) 461-465.

[19] L.R. Bordajandi, J.J. Ramos, J. Sanz, M.J. Gonzalez, L. Ramos, J. Chromatogr. A 1186 (2008) 312-324.

[20] J. Ha, D. Seo, D. Shin, Talanta 85 (2011) 252-258.

[21] P. Korytár, L.L.P. van Stee, P.E.G. Leonards, J. de Boer, U.A.T. Brinkman, J. Chromatogr. A 994 (2003) 179-189.

[22] P. Korytar, P. Haglund, J. Deboer, U. Brinkman, TrAC Trends Anal. Chem. 25 (2006) 373-396.

[23] S.M. Song, P. Marriott, A. Kotsos, O.H. Drummer, P. Wynne, Forensic Sci. Int $143(2004)$ 87-101.

[24] J. Dallüge, J. Beens, U.A.T. Brinkman, J. Chromatogr. A 1000 (2003) 69-108.

[25] L. Drabova, J. Pulkrabova, K. Kalachova, M. Tomaniova, V. Kocourek, J. Hajslova, Talanta 100 (2012) 207-216

[26] UNEP. 〈http://chm.pops.int/Implementation/GlobalMonitoringPlan/Overview/ tabid/83/Default.aspx>.

[27] J. Omar, I. Alonso, M. Olivares, A. Vallejo, N. Etxebarria, Talanta 88 (2012) $145-151$.

[28] K. Oukebdane, F. Portet-Koltalo, N. Machour, F. Dionnet, P. Desbène, Talanta 82 (2010) 227-236.

[29] Y. Li, T. Pang, Z. Guo, Y. Li, X. Wang, J. Deng, K. Zhong, X. Lu, G. Xu, Talanta 81 (2010) 650-656.

[30] A. Fromberg, T. Cederberg, G. Hilbert, A. Büchert, Chemosphere 40 (2000) $1227-1232$. 